\title{
Aerodynamic Effects and Modeling of Damage to Transport Aircraft
}

\author{
Gautam H. Shah* \\ NASA Langley Research Center, Hampton, Virginia 23681
}

\begin{abstract}
A wind tunnel investigation was conducted to measure the aerodynamic effects of damage to lifting and stability/control surfaces of a commercial transport aircraft configuration. The modeling of such effects is necessary for the development of flight control systems to recover aircraft from adverse, damage-related loss-of-control events, as well as for the estimation of aerodynamic characteristics from flight data under such conditions. Damage in the form of partial or total loss of area was applied to the wing, horizontal tail, and vertical tail. Aerodynamic stability and control implications of damage to each surface are presented, to aid in the identification of potential boundaries in 'recoverable' stability or control degradation. The aerodynamic modeling issues raised by the wind tunnel results are discussed, particularly the additional modeling requirements necessitated by asymmetries due to damage, and the potential benefits of such expanded modeling.
\end{abstract}

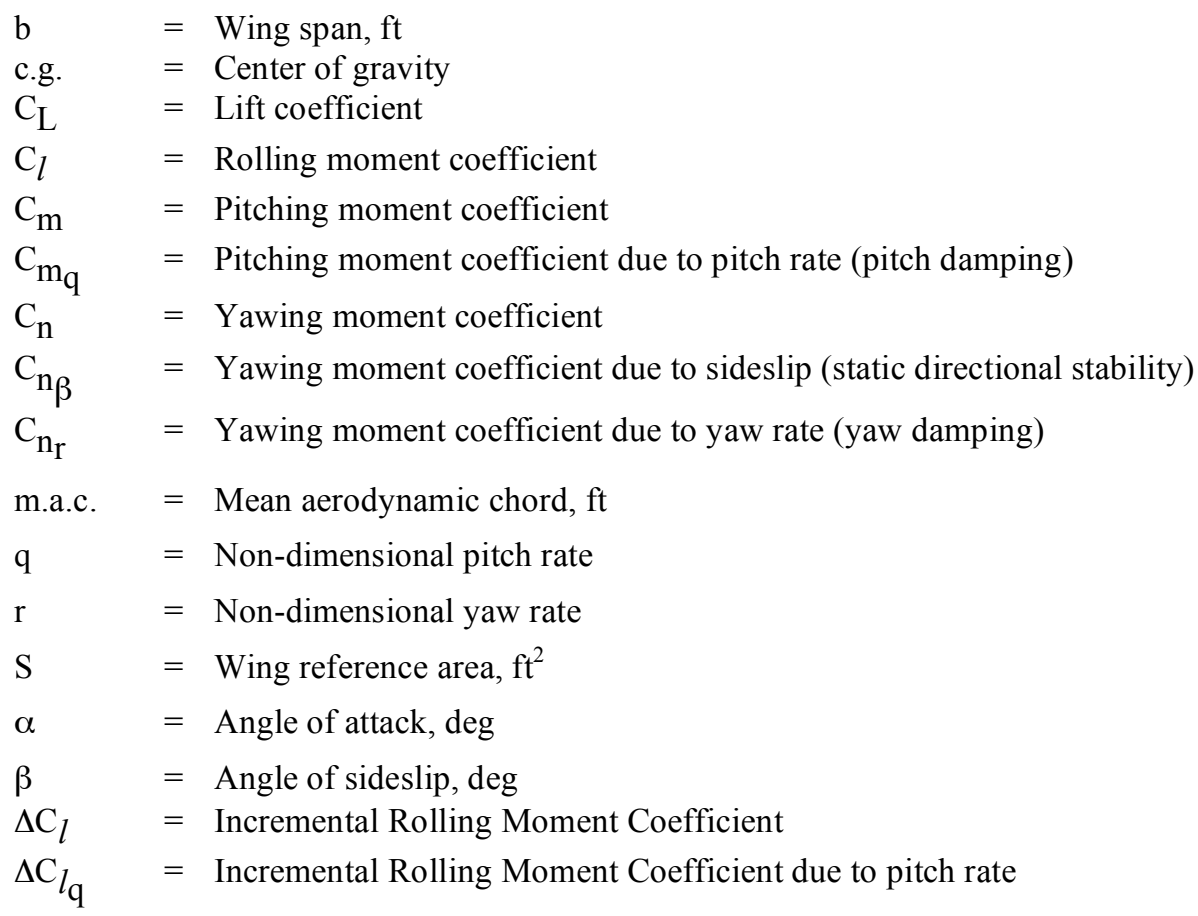

\section{Introduction}

$\mathrm{D}$ AMAGE to, or loss of, aerodynamic or stability/control surfaces of transport aircraft can pose serious implications for continued flight to a safe landing. While such events are not very common, occurrences involving significant damage often result in large numbers of fatalities. Some recent events include:

\footnotetext{
${ }^{*}$ Research Engineer, Flight Dynamics Branch, Mail Stop 308; Senior Member, AIAA
} 
- 1979 - DC-10 Engine separation and resulting asymmetric slat condition, 272 Fatalities $^{1}$

- 1985 - B747 Vertical tail loss, 520 Fatalities $^{2}$

- 1992 - B747 Multiple engine separation and resulting wing damage, 51 Fatalities $^{3}$

- 2001 - A300 Vertical tail loss, 265 Fatalities $^{4}$

- $\quad 2003$ - A300 Wing damage (missile strike), safe landing, no casualties, hull loss ${ }^{5}$

- 2005 - A310 Rudder loss, safe landing, minor casualty ${ }^{6}$


Figure 1. Examples of transport aircraft damage (clockwise from top left): $B 747$ Vertical Tail Loss ${ }^{2}$; DC-10 Engine Loss/Asymmetric Slat ${ }^{1}$; A310 Rudder Loss ${ }^{6}$; A300 Wing Damage ${ }^{5}$

Beyond the mechanical and/or human factors issues which may have contributed to events such as those listed above, recent years have also seen the growing potential threat to civil and military transport aircraft from hostile action using shoulder-fired missiles, or Man-Portable Air Defense Systems (MANPADS) ${ }^{7-9}$. As evidenced by the 2003 DHL A300 event in Iraq, damage from a MANPADS attack can result in severely compromised control capability.

While in some of the cases noted above, the damage caused immediate, unrecoverable loss of control, others resulted in stabilized and controlled (albeit limited) flight capability for at least some duration following the initial event. Enhanced control capability in such situations can increase the possibility of maintaining controlled flight to a safe landing from an otherwise ultimately non-recoverable situation.

The Integrated Resilient Aircraft Control (IRAC) Project of the NASA Aviation Safety Program is conducting research towards the development of flight control capability to recover and safely land an aircraft following an adverse, loss-of-control event or condition, including those due to aircraft damage. IRAC research activities are considering many potential aspects of aircraft control, encompassing integration of aerodynamics, structures, propulsion, and flight planning/guidance issues ${ }^{10}$. 
Flight control system development, verification, and validation require aircraft dynamics models of sufficient fidelity to appropriately reflect the flight characteristics and capabilities of a compromised or damaged aircraft. Outer mold line changes due to damage can result in nonlinear and/or non-symmetric mass properties, aerodynamics, or control characteristics, and it may be difficult to analytically estimate or predict such characteristics or their impact.

An experimental wind tunnel study was undertaken at NASA Langley Research Center under the IRAC project to measure the aerodynamic effects of damage to lifting, stability, and control surfaces of a conventional transport aircraft. The results of the study will be used to develop aerodynamic models of damaged aircraft configurations for use in flight simulation and flight controls development.

Since it is impractical (and impossible) to consider or predict all potential damage conditions, the study focused on tip damage and trailing edge damage to the wing and horizontal and vertical tails. Damage levels ranged from minor to extreme, in order to encompass the boundaries of "controllable" damage.

As this is the initial effort to quantify damage effects, this study focused solely on the aerodynamic aspects of damage; it is recognized that to fully model or predict the flight characteristics under damaged conditions, one must also consider integrated structural, propulsive, and systems effects on the aircraft response. Further studies within the IRAC project will address those aspects.

\section{Test Description}

Wind tunnel tests were conducted on a $5.5 \%$-scale, twin-engine commercial transport configuration in the NASA Langley 14 by 22 Foot Subsonic Tunnel. Conventional static tests were conducted at a dynamic pressure of 10 $\mathrm{lb} / \mathrm{ft}^{2}$, corresponding to a Reynolds Number of $0.54 \times 10^{6}$ based on mean aerodynamic chord. Forced oscillation tests were also conducted in this facility. The model was oscillated in a sinusoidal fashion at frequencies and amplitudes that correspond to typical full-scale short-period and Dutch-roll motions. Oscillation tests were conducted individually in the pitch and yaw body axes to acquire aerodynamic damping characteristics. For all static and dynamic tests, six-component force and moment data were acquired using an internal strain-gauge balance.

The basic (undamaged) configuration had been previously tested extensively under the NASA Aviation Safety Program to quantify aerodynamic and control characteristics over a broad angle of attack and sideslip range for lossof-control and upset recovery modeling research. Detailed information on testing conditions, general aerodynamics, and modeling results of the basic configuration are available in published reports ${ }^{11-13}$.

For this test, damage to the left wing, left horizontal tail, and vertical tail were studied. 'Damage' is defined as a partial or total loss of the surface of interest. Types of damage include tip loss (chordwise cuts along the span), trailing-edge surface (flap, elevator, or rudder) loss, and large holes in the surface. The damage configurations studied were tested individually; simultaneous or multiple damage conditions (e.g., a hole combined with tip loss, or combined wing and tail damage) were not evaluated. Model geometry information and damage conditions, as well as installation photographs, are presented in Figs. 2 and 3 and Tables 1 and 2. 


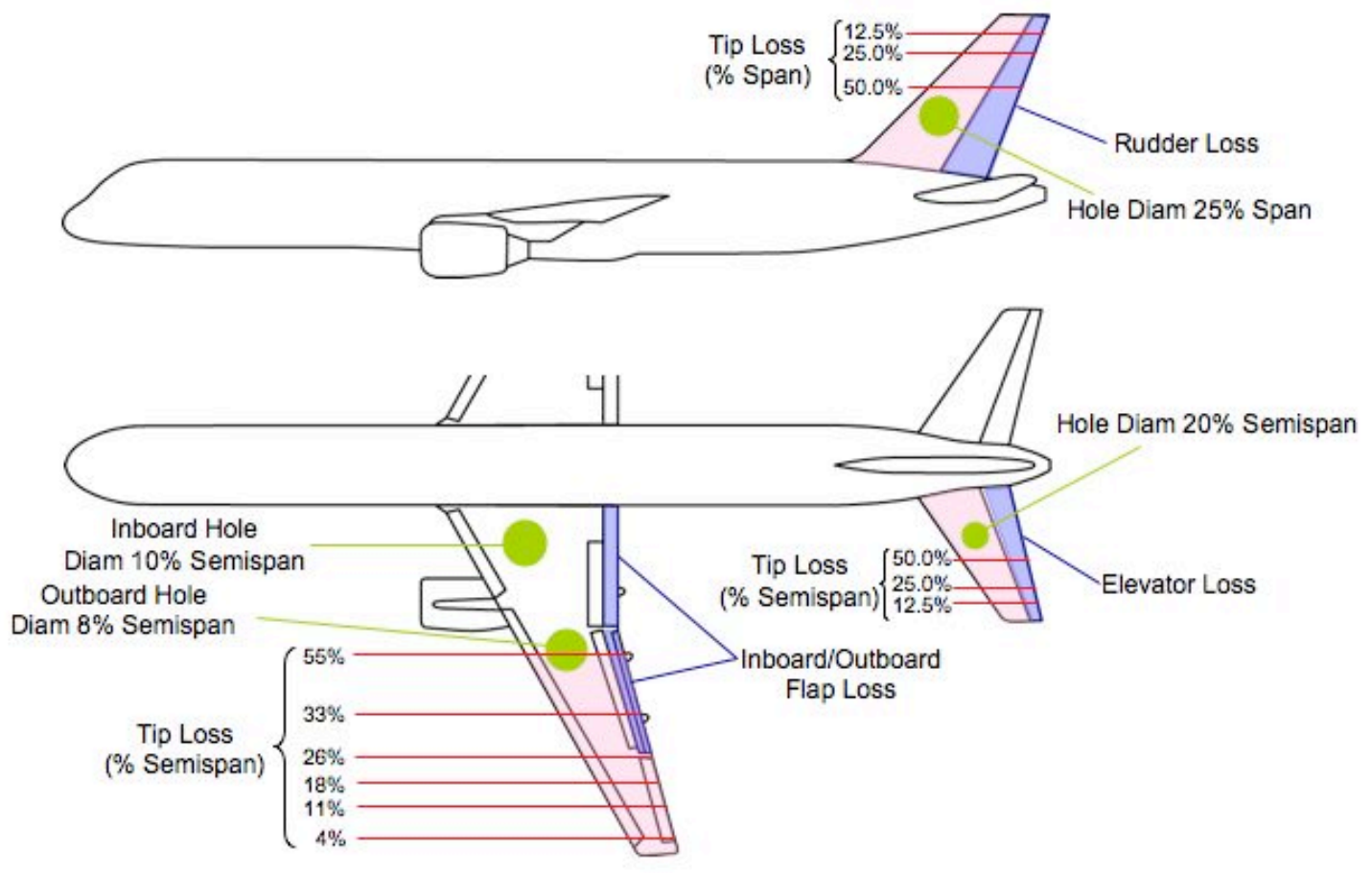

Figure 2. Model Sketch and Damage Conditions Tested

Table 1. Reference Geometry

\begin{tabular}{|c|c|}
\hline Dimension & Value \\
\hline Wing Ref Area $\mathrm{S}, \mathrm{ft}^{2}$ & 5.902 \\
\hline Wing Span b, $\mathrm{ft}$ & 6.849 \\
\hline$\overline{\mathrm{c}}$, or m.a.c., $\mathrm{ft}$ & 0.915 \\
\hline
\end{tabular}

Table 2. Damage Conditions (Tested Individually)

\begin{tabular}{|c|c|c|}
\hline Left Wing & Left Horizontal Tail & Vertical Tail \\
\hline $\begin{array}{l}\text { - Tip Loss } 4 \% \text { Semispan } \\
\text { - Tip Loss } 11 \% \text { Semispan } \\
\text { - Tip Loss } 18 \% \text { Semispan } \\
\text { - Tip Loss } 26 \% \text { Semispan } \\
\text { - Tip Loss } 33 \% \text { Semispan } \\
\text { - Tip Loss } 55 \% \text { Semispan } \\
\text { - Inboard Flap Loss } \\
\text { - Outboard Flap Loss } \\
\text { - Hole Inboard of Engine } \\
\text { - Hole Outboard of Engine }\end{array}$ & $\begin{array}{l}\text { - Tip Loss } 12.5 \% \text { Semispan } \\
\text { - Tip Loss } 25 \% \text { Semispan } \\
\text { - Tip Loss 50\% Semispan } \\
\text { - Full Left Horizontal Tail Loss } \\
\text { - Left Elevator Loss } \\
\text { - Hole at } 40 \% \text { Semispan }\end{array}$ & $\begin{array}{l}\text { - Tip Loss } 12.5 \% \text { Semispan } \\
\text { - Tip Loss } 25 \% \text { Semispan } \\
\text { - Tip Loss 50\% Semispan } \\
\text { - Full Vertical Tail Loss } \\
\text { - Rudder Loss } \\
\text { - Hole at } 35 \% \text { Span }\end{array}$ \\
\hline
\end{tabular}




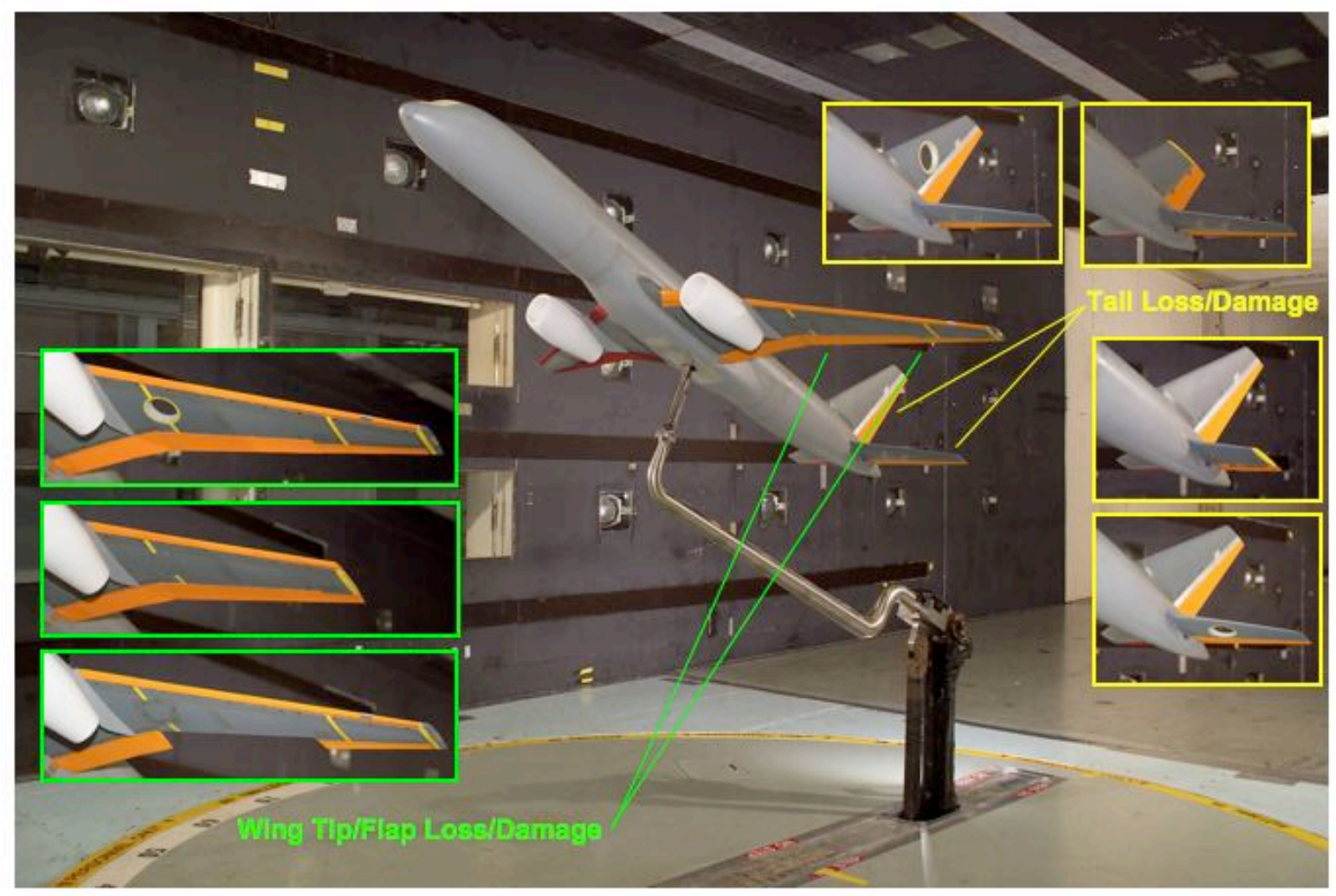

Figure 3. Transport configuration in NASA Langley 14 by 22 Foot Subsonic Tunnel with representative damage conditions

\section{Discussion of Results}

The aerodynamic effects of damage are presented for each surface, and is followed by a discussion of the resulting modeling issues and implications. In the discussion, particular emphasis is placed on the effect of tip loss, given its quantifiable nature. It is difficult to assess the specific aerodynamic effect of flow-through hole damage, since the effect of such damage may vary widely, based on size and location. Therefore, hole damage is provided primarily for reference purposes, to gauge its comparative effect relative to tip or trailing-edge surface loss.

\section{A. Horizontal Tail (Stabilizer) Damage}

Stabilizer damage primarily affects the aircraft's longitudinal stability characteristics, but due to its potential asymmetric nature, off-axis control can also be influenced. Figure 4 shows static longitudinal stability in terms of pitching moment versus lift coefficient for a nominal center of gravity of $25 \%$ m.a.c. for several damage cases. A progressive loss in stability (decreasing negative slope) is seen with increasing loss of stabilizer area. The exception is the elevator-off case, where the degradation is less than expected based on the amount of area loss. A possible explanation is that remaining high-aspect-ratio planform in this condition is more aerodynamically effective than a shorter span of equal area. Figure 5 presents the reduction in longitudinal stability due to tip loss in terms of static margin (in percent m.a.c.). Assuming linear behavior between the tested conditions, tip loss of approximately $70 \%$ will result in longitudinal stability characteristics at a nominal c.g. would be similar to those experienced with an aircraft loaded to its aft c.g. limit. An aircraft initially loaded to near its aft c.g. limit will experience marginally stable or possibly unstable characteristics with smaller levels of damage/area loss.

Since stabilizer damage can also mean partial and/or asymmetric loss of elevator control, changes in longitudinal trim capability will also occur. The asymmetric planform geometry will also generate rolling moment increments in both basic aerodynamic characteristics as well as from elevator deflection, requiring compensating lateral control from longitudinal control inputs or angle of attack variation. 


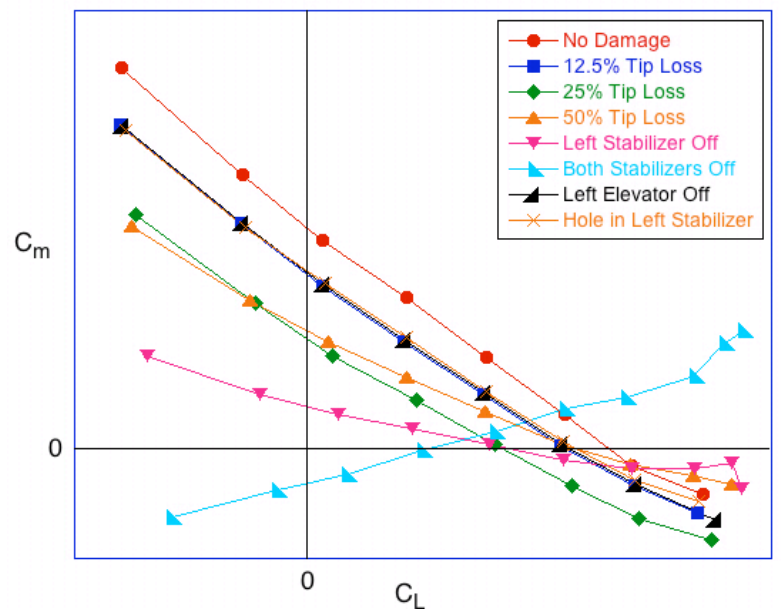

Figure 4. Stabilizer Damage Static Longitudinal Stability

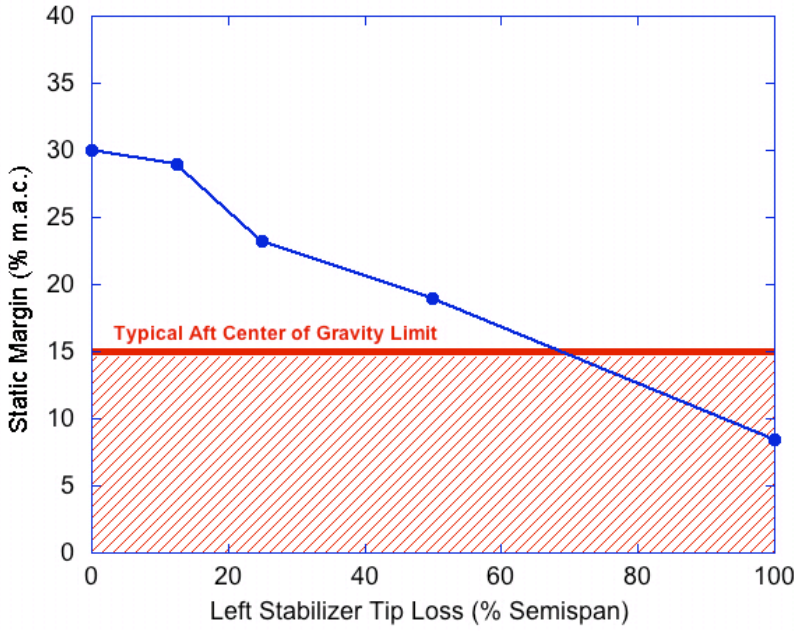

Figure 5. Stabilizer Damage - Static Margin

The effect on longitudinal dynamic stability is shown in Fig. 6, which presents pitch damping over the angle of attack range for damaged and undamaged cases. Similar to the static case, the relatively linear reduction in damping with tip loss indicates reduction loss in pitch damping is roughly proportional to area loss, reaching neutral dynamic stability in the extreme case of a loss of both stabilizers. This linear trend in damping loss is consistent throughout the angle of attack range.

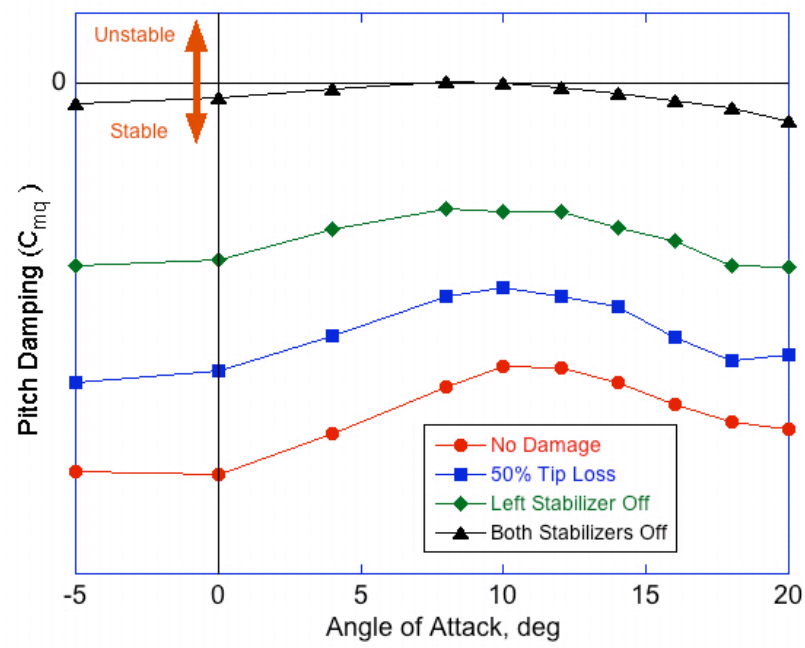

Figure 6. Stabilizer Damage - Pitch Damping

The geometric asymmetry from stabilizer damage also results in unequal contributions to pitch damping from the left and right stabilizers, generating a rolling moment coefficient increment due to pitch rate. Figure 7 shows this increment, $\Delta \mathrm{C}_{l_{\mathrm{q}}}$, for large damage conditions. To quantify the relative magnitude of this effect for full-scale flight conditions, the rolling moment increment as a function of pitch rate at a nominal airspeed of 200 knots was computed, and is presented in Fig. 8 as a percentage of total rolling moment available from full (left + right) aileron deflection. For a completely missing stabilizer, at a typical maximum pitch rate of 5-6 deg/s, potentially 5\% of available control power would be required to actively compensate for the induced rolling moment. Although this is a small value, the effect can be exacerbated by the larger pitch excursions due to the reduced pitch damping or diminished longitudinal control. 


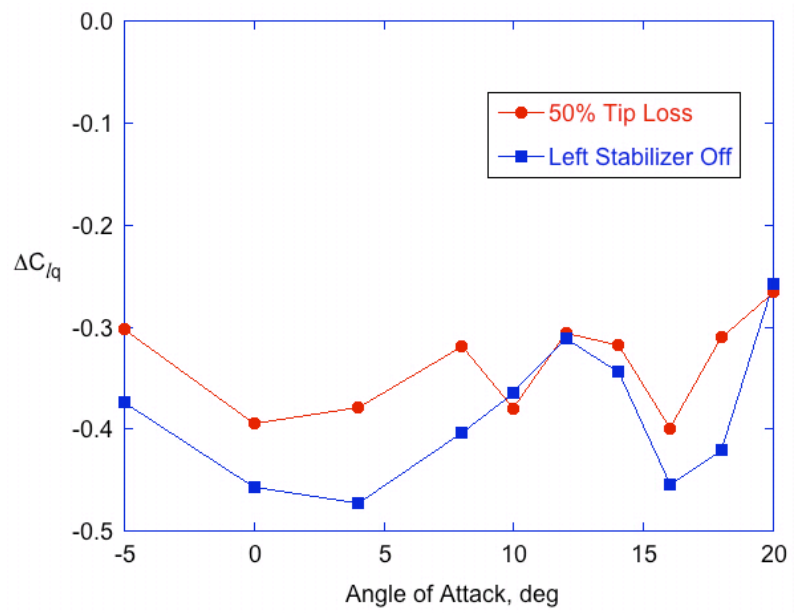

Figure 7. Stabilizer Damage - Incremental Rolling Moment Due to Pitch Rate

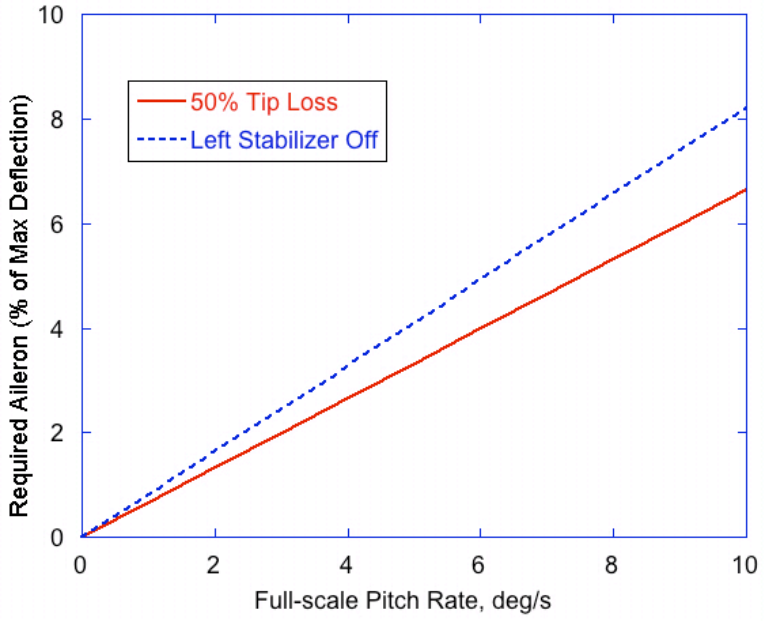

Figure 8. Stabilizer Damage - Aileron Required to Compensate for $\Delta \mathrm{C}_{l q}$

\section{B. Vertical Tail Damage}

The general effects of vertical tail damage on directional characteristics are similar in nature to those seen in the pitch axis from stabilizer damage, namely, a reduction in static and dynamic stability. At zero angle of attack, a progressive reduction in static directional stability (slope of Cn vs beta) is seen with increasing damage/area loss, with no change in trend (fig. 9). All damage cases exhibit a large linear stability region, extending up to moderate sideslip, except for rudder loss, where non-linearity occurs at lower sideslip than the other cases. Complete vertical tail loss, as expected, results in static instability. Figure 10 provides directional stability variation over the entire angle of attack range, where $\mathrm{C}_{\mathrm{n} \beta}$ is computed as the linear slope in yawing moment between sideslip angles of $-4^{\circ}$ and $+4^{\circ}$. The relative degradation due to damage remains generally consistent throughout the angle of attack range.

Vertical tail damage can also result in a reduction in rudder control effectiveness, either directly from partial loss of rudder area, or indirectly from disrupted airflow over the surface caused by upstream damage on the vertical tail. Decreases in rudder effectiveness can have implications for crosswind landing capability or the ability to compensate for engine thrust asymmetries.

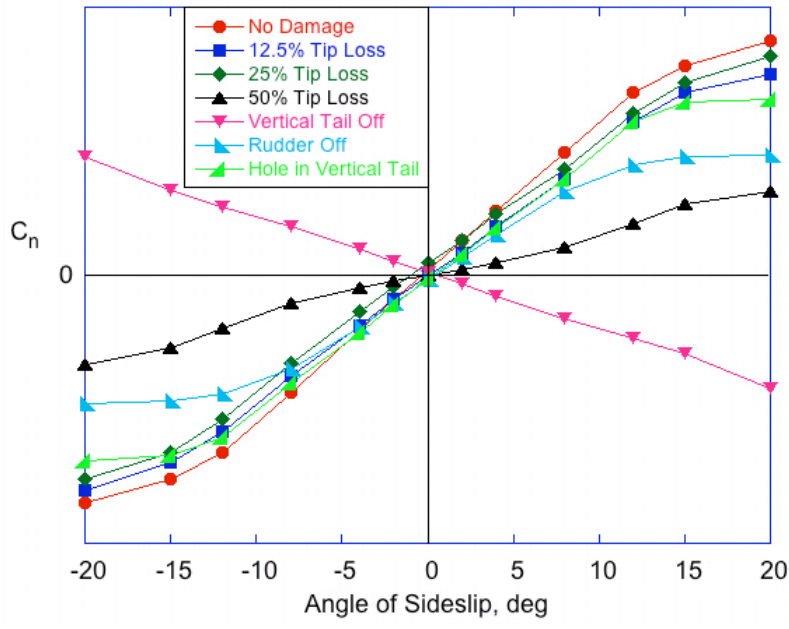

Figure 9. Vertical Tail Damage - Yawing Moment versus Sideslip, $\alpha=0^{\circ}$

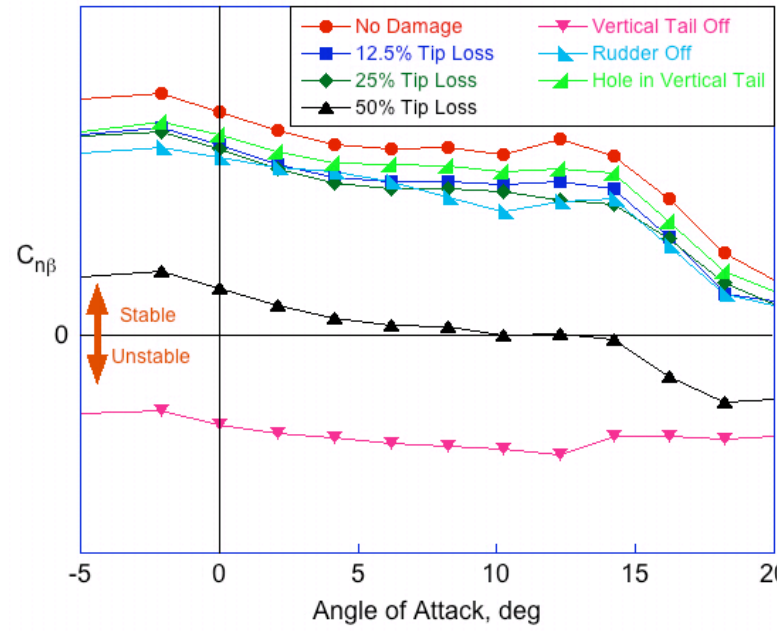

Figure 10. Vertical Tail Damage Static Directional Stability 
Yaw damping characteristics (Fig. 11) exhibit behavior similar to the static characteristics, namely, a consistent degradation throughout the angle of attack range. Static and dynamic stability are summarized in Fig. 12, which shows that the reductions in stability are generally proportional to the area loss (the anomalous value at $25 \%$ tip loss, however, warrants further study).



Figure 11. Vertical Tail Damage - Yaw Damping

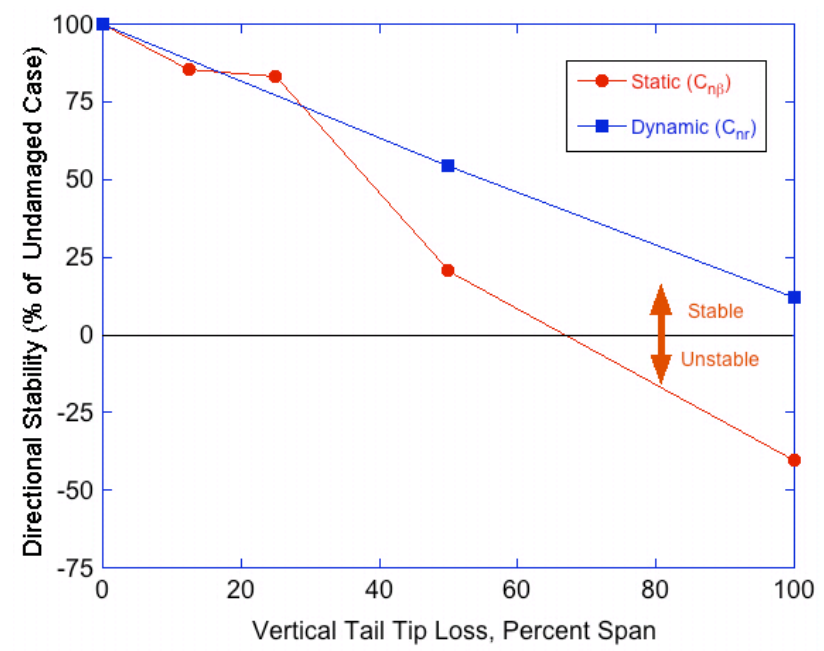

Figure 12. Vertical Tail Damage Stability Summary

Overall, vertical tail damage can have serious stability and control implications and may result in poor directional handling qualities, an inability to maintain heading, and large sideslip excursions. Due to the typically large effective dihedral $\left(\mathrm{C}_{l_{\beta}}\right)$ of swept-wing transport aircraft, the sideslip excursions will also result in potentially large uncommanded rolling motions as well (in essence, a reduction in Dutch Roll stability).

Because the vertical tail is generally the only source of aerodynamic directional stability for a transport aircraft, damage to the tail is difficult to compensate through other means, exacerbating the potentially serious implications for recovery to an eventual safe landing. However, since it is on the aircraft centerline, vertical tail damage will induce minimal asymmetry complications.

\section{Wing Damage}

Unlike tail damage, damage/area loss to the wing results in lift and lateral control limitations, as opposed to significant stability implications. Figure 13a shows lift coefficient versus angle of attack for increasing levels of wingtip loss. A progressive reduction in lift curve slope is seen throughout the angle of attack range, up to and beyond the stall break at approximately $\alpha=10^{\circ}$. With the exception of the $55 \%$ tip loss case, the lift loss due to damage can be compensated for with only a modest increase in angle of attack. The effect of tip loss on effective dihedral $\left(\mathrm{C}_{l_{\beta}}\right)$ is shown in Fig.13b, as rolling moment coefficient versus sideslip for $\alpha=0^{\circ}$, where a negative slope indicates static stability. In the low and moderate sideslip region, only a small reduction in stability is noted, though the effect increases for large-damage cases at large negative (damaged-wing-forward) sideslip angles. 


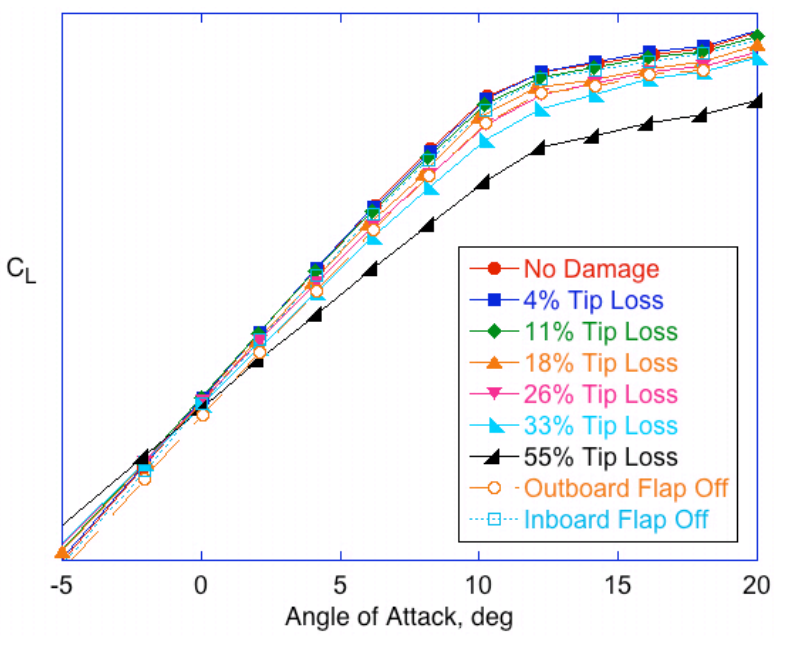

Figure 13a. Wing Damage - Lift Coefficient

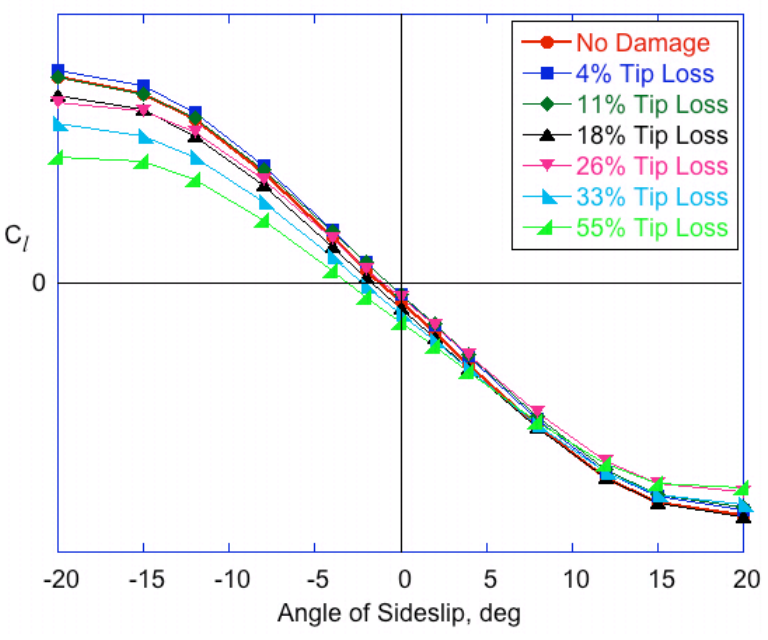

Figure 13b. Wing Damage - Rolling Moment versus Sideslip, $\alpha=0^{\circ}$

The resultant roll asymmetry, however, will impose the more critical limitations on flying capability. Figure 14 shows the incremental rolling moment due to tip loss. The asymmetry increases substantially with both angle of attack and level of damage. Also shown in the figure is the maximum incremental rolling moment that can be generated by deflection of the opposing (undamaged-wing) aileron to compensate for the asymmetry. The compensating rolling moment is actually a positive value, but the sign has been reversed for clarity, to show its magnitude compared to the damage-induced asymmetry. Similar rolling moment asymmetry from flap loss or hole damage is given in Fig. 15.

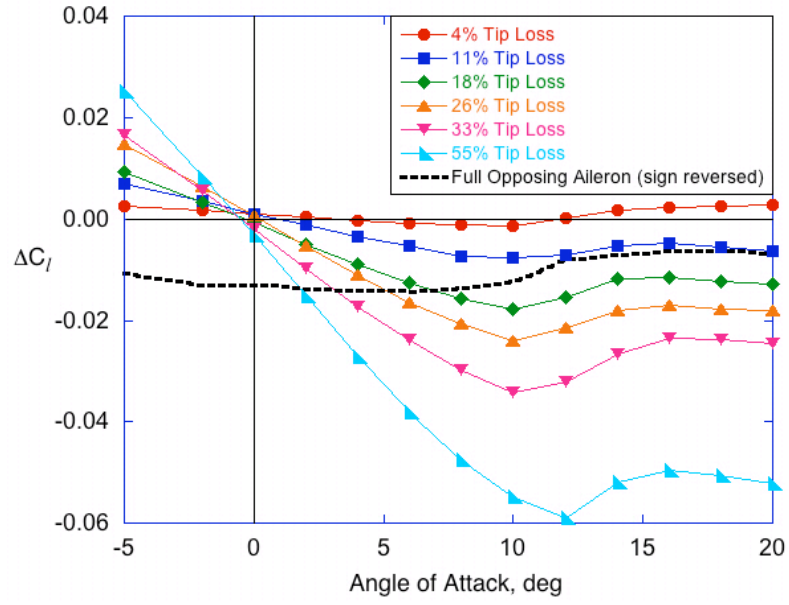

Figure 14. Wing Damage - Incremental Rolling Moment from Tip Loss

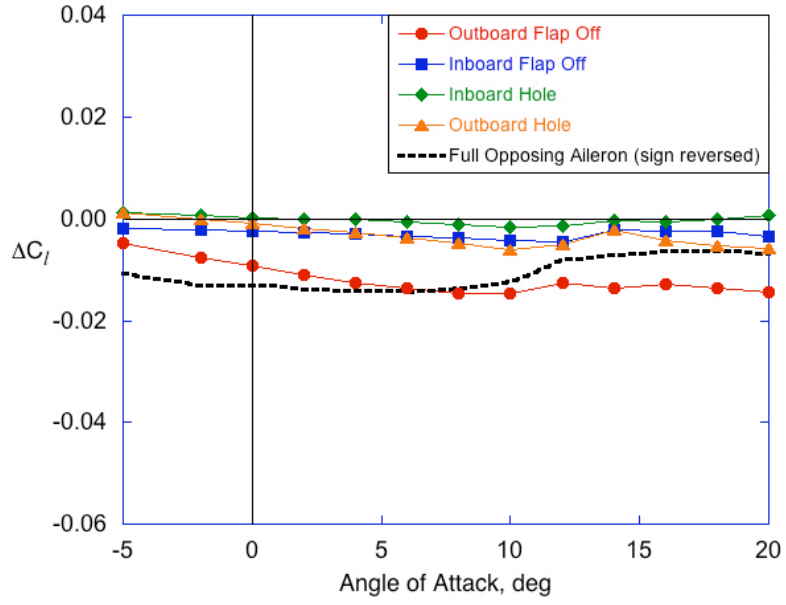

Figure 15. Wing Damage - Incremental Rolling Moment from Flap Loss or Hole

Assuming the aileron on the damaged wing is non-functional (or nonexistent) and no other roll control mechanism available, the opposing aileron control power would be the total available for asymmetry compensation. The intersection of the 'compensating aileron' curve with each damage curve identifies the maximum angle of attack at which roll control can be maintained for that amount of tip loss. Thus the allowable angle of attack range is severely restricted for moderate or large levels of wing damage.

However, the large effective dihedral $\left(\mathrm{C}_{l \beta}\right.$, shown in Fig. 13b) of a swept-wing transport can be exploited to expand the restricted angle-of-attack envelope. The induced rolling moment due to sideslip can be used to compensate for some or all of the rolling moment asymmetry from the wing damage. Figure 16 shows the total 
incremental rolling moment due to tip loss and $-4^{\circ}$ of sideslip (damaged wing forward) relative to the undamaged airplane at $0^{\circ}$ sideslip. Comparison of this figure with Fig. 14 indicates that the maximum allowable angle of attack has increased significantly, demonstrating the effectiveness of the use of sideslip in providing compensating rolling moment. The example of $4^{\circ}$ of sideslip discussed here can be generated with approximately $15 \%$ of the total range of rudder deflection (about the same level of deflection authority typically allotted to a yaw damper).

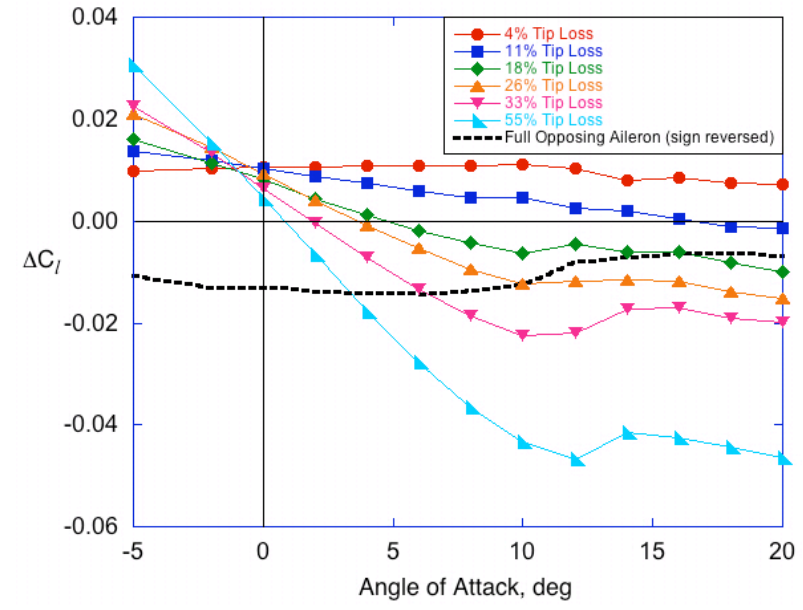

Figure 16. Wing Damage - Incremental Rolling Moment from Tip Loss and $-4^{\circ}$ Sideslip

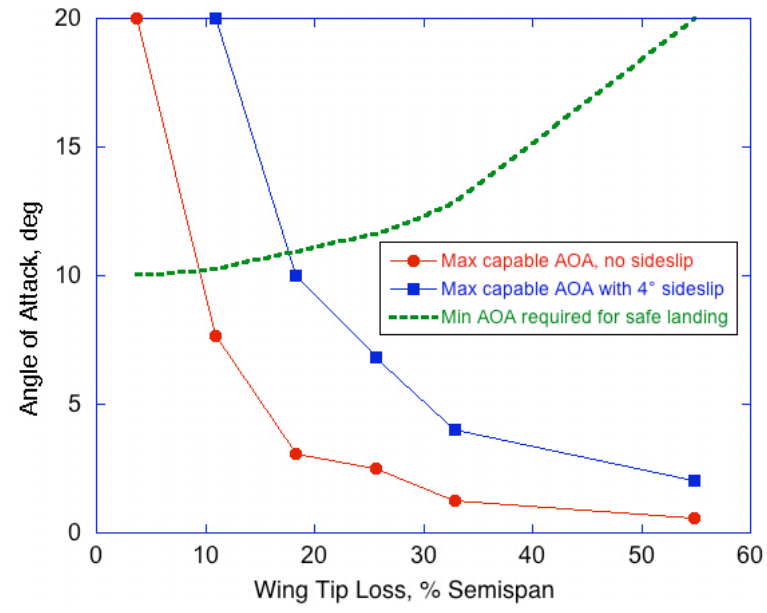

Figure 17. Wing Damage - Angle of Attack Restrictions

It is impractical, however, to consider that full aileron control would be available to help compensate for the roll asymmetry (whether alone or in conjunction with sideslip), since some level of roll control still needs to be available to maneuver the aircraft. Therefore, the realistic angle of attack restriction is actually greater than that defined by the intersection of the aileron and damage curves, and is determined based on the level of roll control required for maneuvering. As an example, if one assumes that $50 \%$ of total roll control power needs to be retained for maneuvering, the maximum angle of attack capable for each damage condition, using only $50 \%$ of the total aileron rolling moment (based on Figs. 14 and 16) for asymmetry compensation, is shown in Fig. 17, as a function of percent tip loss.

The effect of wing damage on the angle of attack required to land is also shown in Fig. 17, and is seen to increase with damage level. The required angle of attack was computed as that needed to achieve the same landing speed as an undamaged aircraft in a clean (no-flap) condition, and based on the damaged lift coefficients from Fig. 13. For moderate and large levels of wing damage, the deficit between 'capable' and 'required' angles of attack implies that although it may be possible to stabilize and control the aircraft at high speed (stay below the 'max capable' curve), it may not be possible to slow the aircraft sufficiently (move above the 'min required' curve) while maintaining control to allow a safe landing.

In general, the 'capable' AOA curve can be moved upwards and to the right (thus expanding the angle of attack envelope) through such means as increasing available roll control power (e.g., spoilers, differential flaps or slats), or greater allocation of available control power to asymmetry compensation, or greater sideslip. In a similar fashion, the 'required' AOA curve can be lowered through methods such as symmetric deployment of high-lift systems. Figure 18 shows, in a generic sense, some of the other limiting conditions and factors which can influence them. 


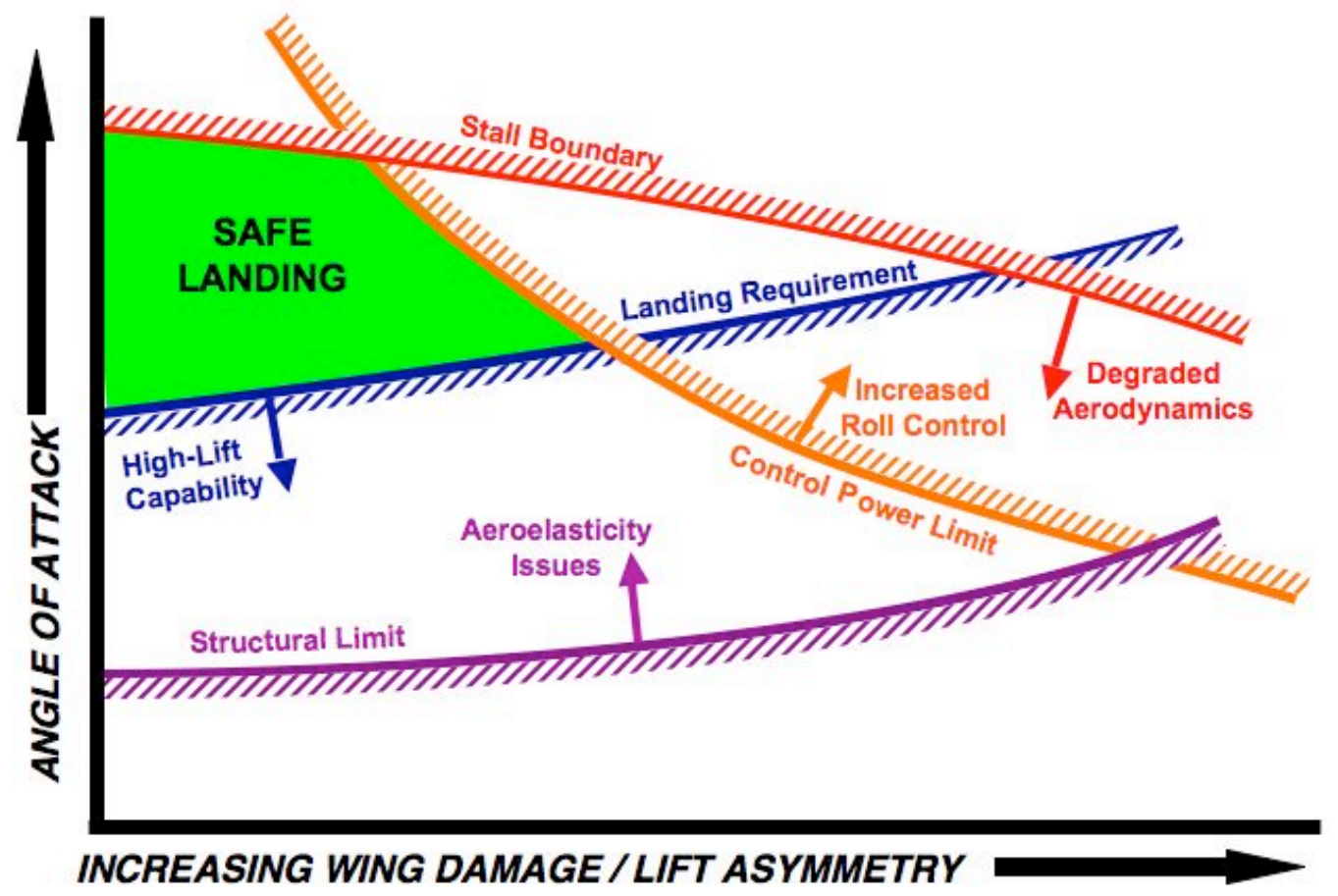

Figure 18. Notional envelope and restrictions for wing damage/lift asymmetry conditions

Similar to the effects from asymmetric stabilizer damage, the lift asymmetry from wing damage will generate rolling moments during pitching motions due to unequal normal force damping contributions from the left and right wings. In the same fashion as Fig. $7, \Delta \mathrm{C}_{l_{\mathrm{q}}}$ for the maximum damage case of 55\% wing loss is shown in Fig. 19. Figure 20 shows the percent of maximum aileron as a function of pitch rate for angles of attack of 4 and 10 (but unlike Fig. 8, it is shown relative to a single aileron, since it is assumed the damage-wing aileron is non-existent). A significant amount of total aileron is required for pitch rates of 5-6 deg/sec, but again, this is for an extreme wing damage case. Smaller damage levels would be expected to result in much lower, aileron requirements.

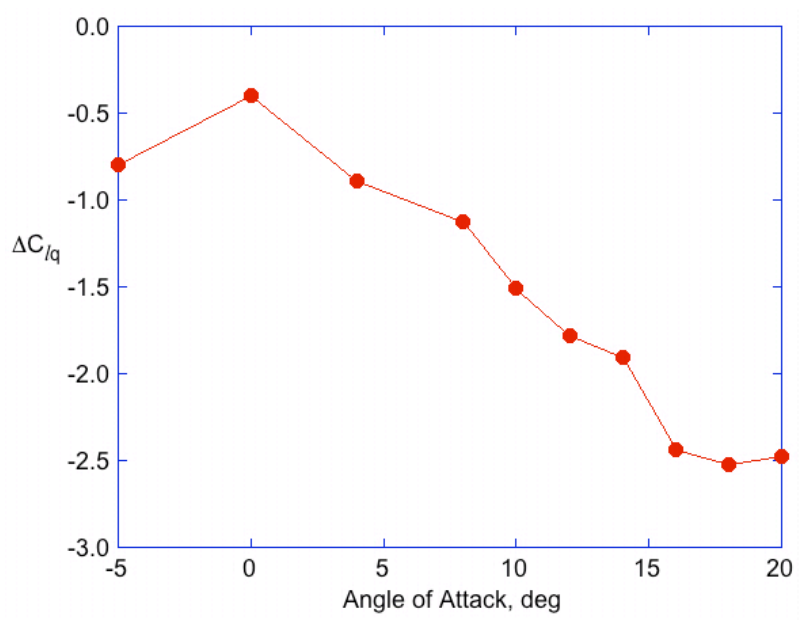

Figure 19. Wing Damage - Incremental Rolling Moment Due to Pitch Rate for 55\% Wing Tip Loss

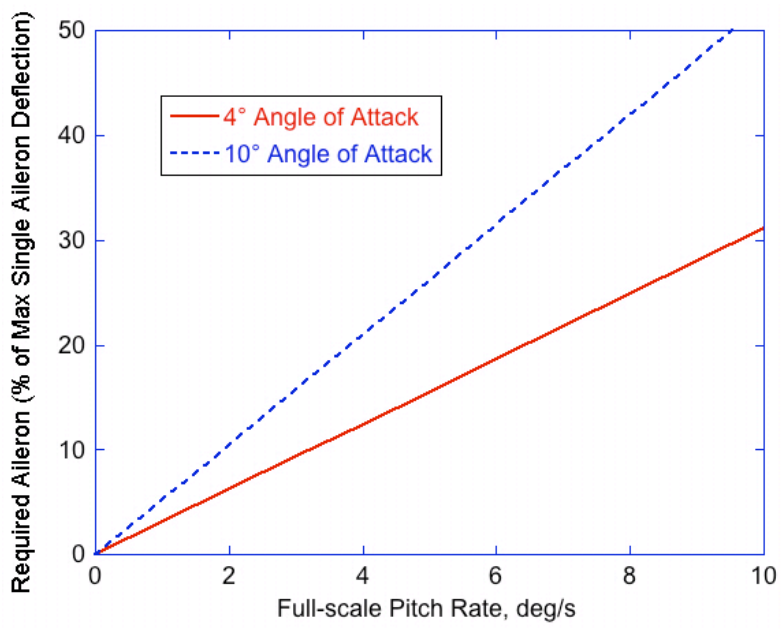

Figure 20. Wing Damage - Aileron Required To Compensate for $\Delta \mathrm{C}_{l q}$ for $55 \%$ Wing Tip Loss 


\section{Modeling Issues}

The results of this wind tunnel investigation raise several issues which must be considered for appropriate modeling of aerodynamic characteristics under damaged conditions, all generally related to the asymmetries created in the configuration and resultant aerodynamics.

For all damage cases, modeling of very abrupt or step change in mass properties, both in magnitude and location, is required. With the exception of vertical tail damage, the conditions studied herein all result in spanwise asymmetry of the aircraft, and hence a shift in center of gravity and other mass properties away from the aircraft centerline/plane of symmetry. Since simplifications of the general equations of motion used for aircraft flight dynamics research generally involve assumptions of symmetry, it is important to ensure that the effects on all mass properties due to lateral c.g. offsets are appropriately modeled and accounted for. Some recent research activities have addressed this aspect ${ }^{14}$.

From an aerodynamic modeling standpoint, many assumptions of symmetry may no longer be valid due to the off-axis influences of damage, and new aerodynamic contributions will need to be modeled. Some (but certainly not all) of the additional aspects which need to be considered are:

Asymmetric horizontal tail damage:

- Rolling or yawing moment variation with angle of attack

- Rolling moment due to asymmetric elevator control power or deflection may require modeling of individual left and right stabilizer/elevator characteristics instead of as a combined surface

- Rolling moment from pitch rate due to asymmetric damping contribution

Asymmetric Wing damage:

- General aerodynamic characteristics in all axes may be non-symmetric with sideslip

- Modeling of individual aileron control power characteristics instead of as combined surfaces

- Modeling of flap and slat effects individually, to allow for asymmetric flap or slat deployment

- Rolling moment from pitch rate due to asymmetric normal force damping

- Because of asymmetric lift from the wings, roll damping will no longer be symmetric with rate - damping from positive and negative roll rates will not be the same.

The multi-axis coupling effects will also influence control allocation schemes in flight control development, as controls which previously were dedicated to a specific axis may now need to be partially allotted to another axis to compensate for such effects. In general, it may prove beneficial to individually model as many control surfaces as possible, not only to allow proper prediction of off-axis effects, but also to facilitate their use for more complex, multi-axis control allocation schemes.

Another aspect for consideration, which underscores the importance of correct modeling, are the implications that non-symmetric aerodynamic effects can have for parameter estimation from flight data of a damaged aircraft. If important induced off-axis characteristics are not appropriately considered in the model structure, their effects can be erroneously attributed to other existing aerodynamic contributors, resulting in poor correlation to their predicted values.

\section{Concluding Remarks}

A wind tunnel study was conducted to measure the aerodynamic effects of damage on a commercial transport configuration. The primary effects of damage to tail surfaces are on stability characteristics, while the main effects are control-related for wing damage. Asymmetries created due to damage can have implications for modeling of mass properties as well as aerodynamics; off-axis influences to stability and control power can potentially complicate controllability and recoverability. Appropriate modeling of such effects is critical for flight control development as well as parameter estimation from flight data, and emphasizes the need and benefits of individual modeling of flight control surfaces. In addition to aerodynamics modeling, it is important to recognize that a fully integrated modeling of aerodynamic, structural, propulsive, and systems effects is necessary for a high-fidelity prediction of flight characteristics under damaged conditions. 


\section{References}

${ }^{1}$ National Transportation Safety Board Report AAR-79-17, Washington DC, 1979.

${ }^{2}$ Job, Macarthur, Air Disaster, Volume 2, Aerospace Publications, 1996, pp.136-153.

${ }^{3}$ Netherlands Aviation Safety Board Aircraft Accident Report 92-11, Amsterdam, Netherlands, 1992.

${ }^{4}$ National Transportation Safety Board Report AAR-04-04, Washington DC, 2004

${ }_{5}^{5}$ Aviation Week and Space Technology, December 8, 2003.

${ }^{6}$ Transportation Safety Board of Canada Report A05F0047, Gatineau, Quebec, Canada, 2005.

${ }^{7}$ Chow, J., et al., "Protecting Commercial Aviation Against the Shoulder-Fired Missile Threat," RAND Occasional Paper, January 2005.

"“The MANPADS Menace: Combating the Threat to Global Aviation from Man-Portable Air Defense Systems", Fact Sheet, Bureau of Military-Political Affairs, U.S. Department of State, September 2005.

${ }^{9}$ Czarnecki, Greg; Shah, Gautam; and Haas, John.: "Control Surface Vulnerability to MANPADS," in Aircraft Survivability, Joint Aircraft Survivability Program, Arlington VA, Summer 2005, pp. 21-22.

${ }^{10}$ Integrated Resilient Aircraft Control Technical Plan, Aviation Safety Program, Aeronautics Research Mission Directorate, NASA, 2007.

${ }^{11}$ Shah, Gautam H.; Cunningham, Kevin; Foster, John V.; Fremaux, C. Michael; Stewart, Eric C.; Wilborn, James E.; Gato, William; and Pratt, Derek W.: Wind Tunnel Investigation of Commercial Transport Aircraft Aerodynamics at Extreme Flight Conditions. SAE-2002-01-2912, Presented at SAE World Aviation Congress, Phoenix, AZ, November 2002.

${ }^{12}$ Foster, John V., Cunningham, Kevin, Fremaux, Charles M., Shah, Gautam H., Stewart, Eric C., Rivers, Robert A., Wilborn, James E., and Gato, William: Dynamics Modeling and Simulation of Large Transport Airplanes in Upset Conditions, AIAA2005-5933, Presented at 2005 AIAA Guidance, Navigation, and Control Conference, San Francisco, CA, August 2005.

${ }^{13}$ Murch, Austin M. and Foster, John V.: Recent NASA Research on Aerodynamic Modeling of Post- Stall and Spin Dynamics of Large Transport Airplanes, AIAA-2007-0463, Presented at 2007 AIAA Aerospace Sciences Meeting, Reno, NV, January 2007.

${ }^{14}$ Bacon, Barton J. and Gregory, Irene M.: General Equations of Motion for a Damaged Asymmetric Aircraft, AIAA-20076306, Presented at 2007 Atmospheric Flight Mechanics Conference, Hilton Head, SC, August 2007. 